\title{
Assessing Customers Satisfaction of Urban Public Transport Service Delivery in Selected Cities of SNNPRS, Ethiopia
}

\author{
Degwale Gebeyehu Belay \\ Lecturer in the Department of Governance and Development Studies, Bahir Dar University \\ Akalewold Fedilu Mohammed Robera Regassa Kenei \\ Lecturer in the School of Governance and Development Studies, Hawassa University
}

\begin{abstract}
The study is aimed at measuring the level of customers' satisfaction in urban public transport service in three cities of Southern Nations, Nationalities and People's Regional State (SNNPRS) of Ethiopia, namely; Hawassa, Hosana and Sodo. The SERQUAL model which comprises five dimensions of service quality such as; tangibility, reliability, responsiveness, assurance, and empathy has been used to measure the level of customers' satisfaction. The study was conducted based on cross-sectional survey design. A convenient sampling method was also applied to select the sample population. Accordingly, relevant data for the study were collected from 300 urban public transport users. The findings of the study revealed that, the level of transport need for popular mobility is $61 \%$ whereas the overall percentage of customers' satisfaction is $37 \%$. Again, the finding showed that, Bajaj or rickshaw motors is the most preferred and widely used mode of urban public transport by $70 \%$. Generally, the urban public transport service is neither reliable nor tangible or responsive to the customers in all the study areas. This paper is based on an original research which opens eyes for policy makers to increase quality of urban public transport service to its customers. Hence, it helps to identify areas of gaps which need interventions to improve transport quality in urban areas.
\end{abstract}

Keywords: Transport service, urban public transport, Transport Service, Customers' satisfaction.

DOI: $10.7176 / \mathrm{JAAS} / 53-01$

Publication date:March $31^{\text {st }} 2019$

\section{Introduction}

The role of transport service in urban life is innumerable. It plays an importnat role in the day to day life of urban people. It is an engine of the socio-economic and political transformation of cities (Demdime, 2012). Moreover, it provides mobility of the people, goods, access to employment, education, shopping, health and entertainment opportunities. Quality urban public transport can also play an important role in reducing an increasing use of private motorized mode of transport. By doing so, urban transport service doubles the value and quality of urban life. However, this fact is so when there is only effective or satisfactory urban public transport services is delevered to the people or transport users. But, as it is indicated by Sanjay (2016), effective or satisfactory urban public transport service provisions have never been an easy task to many cities of developing countries.

Sustainable urban public transport needs to satisfy the demands of transport users. Since the demand of customers is always increasing, service providers should apply their ultimate potential to make their customers satisfied. However, in the absence of quality urban transport services and competition in the sector, customers' satisfaction is compromised. This would again affect the rights of customers' to get quality services they deem to get. To increase public transport service, the service should be designed and performed in a way it accommodates the levels of service sought by customers (Beirão and Cabral, 2007). As indicated in Fellsson and Friman (2012), customers perceive the quality of public transport based on different factors i.e. reliability, frequency, travel time and fare level, comfort and cleanliness, network coverage/distance to stop, and safety issues. Similarly Palmer and Cole (1995), stated that transportation service users want to consume a comfortable service in agreed time and in a convenient place. They further stated that - Service producers have to be increasingly sure that they are producing the right services, in the right way, in the right places, at the right time, for the right price. Jonson and Clark (2005) also stated that customer satisfaction is the result of customer's comparison of their perception of service delivery with their prior expectations. According to them, to satisfy customers, service providers are required to deliver a service that fulfill customers requirement. To this end, customer satisfaction level is rated as poor if their perception of the actual service is below their expectations (Baron and Harris, 2003).

Transport users (customers) are stakeholders in urban public transport governance and their satisfaction is a priority area in the management of transports system. Moreover, service quality is a critical prerequisite factor that determines the satisfaction of transport users. In the context of public transport research, 'service quality is a measure of how well the service level delivered matches with customer expectations' (Transportation Research Board, 2004). Delivering quality service means conforming to customer expectations on a consistent basis (Berry, 1983). As stated by deOna et al. (2012), service quality is measured primarily from the customer's 
perspective since customers are the only judges of service quality. Hence, transport users will have favorable perception of service quality if the service provided matches or exceeds their expectations. However, their perception will be unfavorable if the service quality is below the expectations.

According to Berry et al (1985), the most acknowledged and applied model in diversity of industries is the SERQUAL (service quality) model. This model proposed five dimensions that can be used to measure quality of services. Nasution (2010) presented these determinants sequentially based on its importance as reliability, responsiveness, assurance, empathy and tangibility.

A study conducted by Ladhari, (2009) suggested that the SERVQUAL model is a good scale to measure service quality in different sectors. Hence, this study is conducted with the objective of measuring the level of customer satisfaction in urban public transport service provision in the three study areas of Southern Nations, Nationalities, and People's Region (SNNPRS) by using the SERVQUAL model which takes customers expectation and their perception of the service into account.

\section{Method}

This study was conducted in Hawassa City, Sodo and Hosana Towns of SNNPRS, Ethiopia. In this study, a cross sectional survey design was applied and 300 transport users were selected of which 100 are selected from each study area. To select the sample population, convenient sampling technique was applied. We have visited different routes at different times of travel in all study areas. Respondents were selected randomly by informing them about the objective of the research and getting their full consent. Since the objective of this study is to measure the level of transport users' satisfaction on urban public transport service provision, a quantitative research approach was used.

Relevant data for the study was collected from both primary and secondary source of data. The primary data was collected through semi-structured questionnaire. The questionnaire was prepared based on international standard measurements of service quality (See Table 1.). On these ground, respondents were asked to rate their satisfaction on the qualities of service they get from urban public transport service. The questionnaire was prepared in English and translated in to Amharic language in which all respondents can understand. On the other hand, secondary data was also collected from published and unpublished secondary sources of information such as articles, reports and web-sources.

Table1: Dimensions and variables to measure service quality

\begin{tabular}{|l|l|}
\hline Dimension & Attribute \\
\hline Reliability & $\begin{array}{l}\text { Ability to perform the promised service dependably and accurately, punctuality, frequency of } \\
\text { public transport to meet requirements of users }\end{array}$ \\
\hline Responsiveness & Willingness to help customer or respond to their demand and provide prompt service \\
\hline Assurance & $\begin{array}{l}\text { Knowledge and courtesy of employees and their ability to instill trust and confidence in } \\
\text { customers }\end{array}$ \\
\hline Empathy & $\begin{array}{l}\text { Caring, individualized attention the firm provide its customer, address customer concern and } \\
\text { needs }\end{array}$ \\
\hline Tangibility & Physical facilities, equipment, and appearance of personnel \\
\hline
\end{tabular}

Source: Literature review, 2017

Depending on the above variables, in this study, attempt has been made to measure the quality of services provided and level of customers satisfaction on urban public transport service in the study area. Accordingly, urban public transport is differently used from the way other writers have been used. Urban public transport is more broadly used to incorporate all major modes of public transportation such as buses, taxis and auto rickshows or three wheeler vehicles irrespective of ownership structure or regulatory basis, while in many instances it is used to refer to mass transport or city bus transportations, which is among the least developed transport sector in many cities and towns of developing countries (Kumar and Barrett, 2008). Hence, in this study, our analysis of customer satisfaction on urban public transport lays on transport users who use the different modes of urban public transport service.

The process of data collection involved two steps. The first step was about the selection of potentially busy routes or points. The second step was about selection of respondents. For the above two steps separate sampling techniques; purposive and convenient sampling technique were used. Purposive sampling technique was used to identify potentially busy routes, points/terminals and pick times where significant number of transport users may be found. On the other hand, convenient sampling technique was used to select individual respondents to administer the questionnaire. Finally, the collected data was analyzed using descriptive statistics i.e. percentage and frequency.

\section{Results}

\subsection{Socio-demographic characteristics of the respondents}

As depicted in table 2, out of the total respondents consulted from all the three study areas, nearly $80 \%$ of them 
were males and the remaining $20 \%$ were females. From all the three study areas, while the highest percentage of female respondent which accounts to $45 \%$ was from Hawassa city, the lowest percentage which only accounts to $4 \%$ was from Sodo town. On the other hand, the reverse of this percentage signals where the highest as well as the lowest percentage of the male respondents were consulted from, which was $96 \%$ and $55 \%$, Sodo and Hawassa city respectively.

The fact bearing careful attention regarding the gender composition of the above figure is that, since the consultation of the respondents was partly out of convenience and proximity to the researchers, it doesn't tell us the gender difference of transport use and has no any implication on the broader gender dimension of urban transport usage. Rather, it might tell us the views expressed in this study dominantly represent the males' views and orientation of urban transport service.

With regard to the age composition of the respondents, the table showed that, in all the three study areas, $66 \%$ or highest number of them were between the age categories of 18-24. Even though, the critical lowest number $(0.3 \%)$ of them is between $55-64$ age category, the moderate lowest number $(18.33 \%)$ of them were between $35-54$ age.

With regard to the occupation of the respondents, the table showed that, the employees represent the largest number $(48.7 \%)$ of the respondents followed by student $(26.7 \%)$. This implies that, about $75 \%$ of the respondents were students and employees. While the 'Others' and 'House Wife' were among the lowest number of the respondents at $1.7 \%$ and $1 \%$ respectively, and nearly equal percentage $(11 \%)$ of the respondents were job seekers and private workers.

Table 2: Gender, age, and occupational status of respondents

\begin{tabular}{|c|c|c|c|c|c|c|c|c|c|}
\hline \multirow{3}{*}{\multicolumn{2}{|c|}{ Characteristics }} & \multicolumn{6}{|c|}{ City/Town } & \multirow{2}{*}{\multicolumn{2}{|c|}{ Total }} \\
\hline & & \multicolumn{2}{|c|}{ Hawassa } & \multicolumn{2}{|c|}{ Hosana } & \multicolumn{2}{|c|}{ Sodo } & & \\
\hline & & Fr. & $\%$ & Fr. & $\%$ & Fr. & $\%$ & Fr. & $\%$ \\
\hline \multirow[t]{2}{*}{ Gender } & Male & 55 & 0.55 & 88 & 0.88 & 96 & 0.96 & 239 & 79.7 \\
\hline & Female & 45 & 0.55 & 12 & 0.12 & 4 & 0.04 & 61 & 20.3 \\
\hline \multicolumn{2}{|l|}{ Total } & 100 & 100.0 & 100 & 100.0 & 100 & 100.0 & 300 & 100.10 \\
\hline \multirow[b]{4}{*}{ Age } & $18-24$ & 34 & 34.0 & 39 & 39.0 & 46 & 46.0 & 119 & 66.3 \\
\hline & $25-34$ & 51 & 51.0 & 36 & 36.0 & 38 & 38.0 & 125 & 41.67 \\
\hline & $35-54$ & 15 & 15.0 & 25 & 25.0 & 15 & 15.0 & 55 & 18.33 \\
\hline & $55-64$ & 0 & 0.0 & 0 & 0.0 & 1 & 1.0 & 1 & 0.3 \\
\hline \multirow{7}{*}{ Occupation } & Student & 37 & 37.0 & 13 & 13.0 & 30 & 30.0 & 80 & 26.7 \\
\hline & Job seeker & 2 & 2.0 & 4 & 4.0 & 26 & 26.0 & 32 & 10.7 \\
\hline & Employee & 59 & 59.0 & 57 & 57.0 & 30 & 30.0 & 146 & 48.7 \\
\hline & Private work & 2 & 2.0 & 20 & 20.0 & 11 & 11.0 & 33 & 11.0 \\
\hline & Housewife & 0 & 0.0 & 2 & 2.0 & 1 & 1.0 & 3 & 1.0 \\
\hline & Retired & 0 & 0.0 & 0 & 0.0 & 1 & 1.0 & 1 & 0.3 \\
\hline & Other & 0 & 0.0 & 4 & 4.0 & 1 & 1.0 & 5 & 1.7 \\
\hline
\end{tabular}

\section{Source: Fieldwork, 2017}

There is no question about the necessity of urban transport at all. In all of the three study areas, there has been significant number of peoples demanding frequently on a daily base. As depicted in the Table 3 , the overall frequency of transport usage on a daily base, in all areas, was accounted at $42 \%$ followed by both $1-2$ and $3-4$ days per week which equally count $19 \%$. With regard to specific city and towns' case, nearly $49 \%$ of the respondents frequently used transport on a daily base from Hawassa city followed by $42 \%$ and $35 \%$ from Hosana and Sodo towns respectively.

Comparatively, though, Sodo town exhibited the lowest frequency of transport usage on a daily base (35\%), on an aggregate level of the three top frequency of transport usage (Every day, 1-2 days per week and 3-4 days per week), it exhibited highest frequency of transport usage at $85 \%$ followed by $78 \%$ and $68 \%$ of Hawassa city and Hosana town respectively.

With regard to preferred mode of urban transport most often used, the finding of the study showed that, while Bajaj was the most preferred mode of transport (70\%) followed by Mini Bus (22\%), City bus (5.3\%) and Damas $(3 \%)$ were rated as the least preferred mode of public transport respectively in all the three study areas. One of the biggest challenges to take this result for grant and make conclusive generalization was the existing number of these modes as well as the functionality of few of them. In Hosana and Sodo towns for instance, the city buses were not functioning. Besides, Damas and minibus are few in number in Hosana town while they are not found in Sodo town.

Concerning with specific city and towns' case, Bajaj still outweighs the other modes of transport. Be it as it may, the finding showed that, the highest percentage of Bajaj mode was used in Hosana town (74\%) followed by 
Sodo town (73\%). In Hawassa city, Bajaj accounts to $62 \%$ followed by $32 \%$ of Mini Bus taxi. This shows that, the availability of other modes of transport (i.e. City bus, Damas, Mini-bus) can reduce the choice of Bajaj as the dominant preferred mode of urban public transport.

Table 3: Urban transport use and preferred mode of urban transport

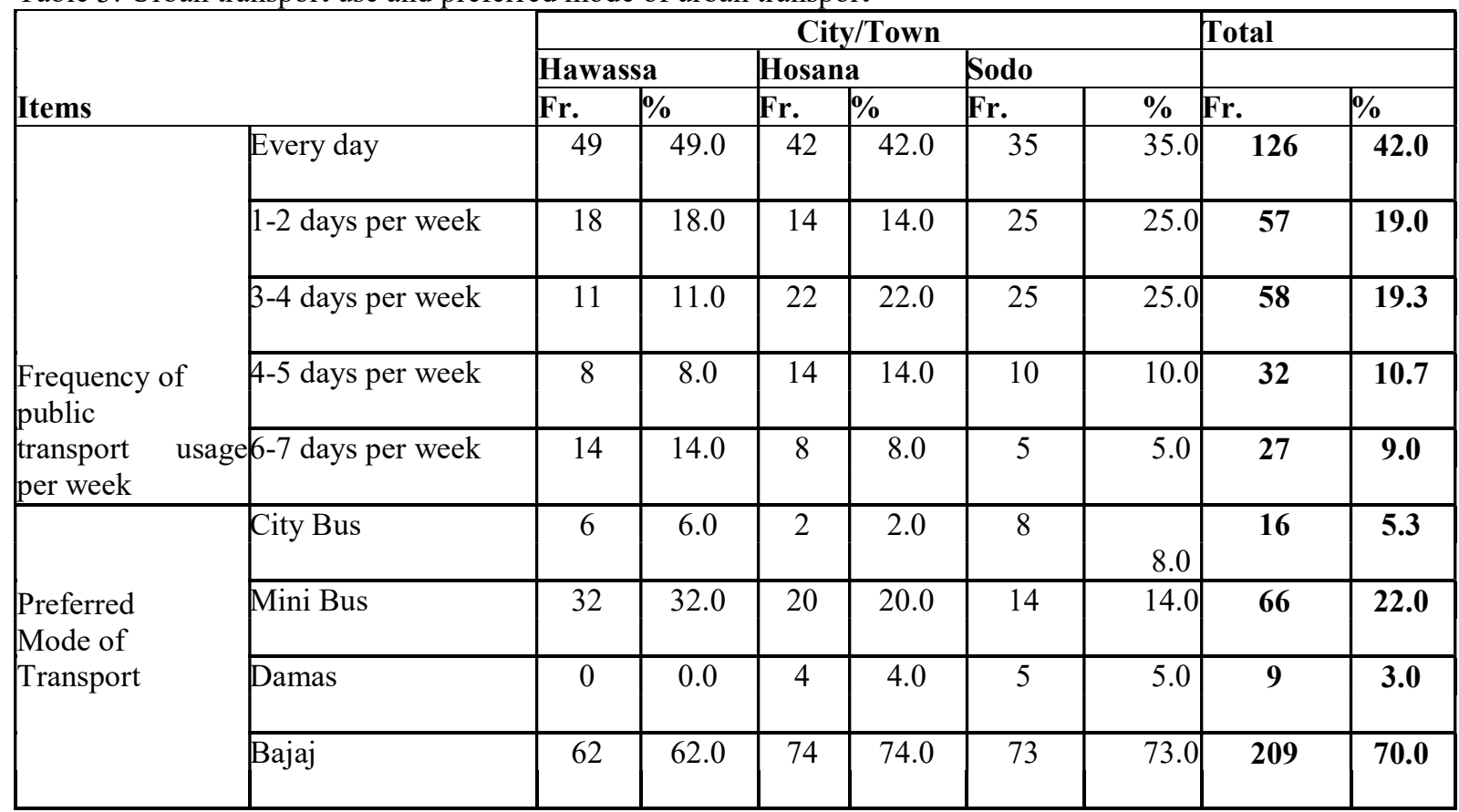

\section{Source: Fieldwork, 2017}

The study also found out that Bajaj is the preferred dominant mode of transport since it is easily available and saves time [it loads only three passengers]; comfortable, no suffocation and crowed; no need of waiting more time to get passenger, and it can travel to any roots compared to other modes. Besides these attractive characteristics of Bajaj, short supply of other modes is also another important factor. Respondents replied that taxis and city buses are not adequately available in cities.

\subsection{Reliability of Urban Public Transport Services}

The finding of the study showed that, the access and availability of urban public transport in all the three study areas were negligible. As indicated in Table 4, out of the total respondents, $28.7 \%$ of them responded that public transport is available in the city/towns. From the three study areas, Hawassa city exhibited the lowest percentage of public transport availability $(16 \%)$ while Hosana town signals the better rate of public transport availability $(36 \%)$.

Similarly, accessibility of public transport upon demand was also rated at the lowest level in all study areas. The finding indicated that, though accessibility upon demand was slightly better than availability within the city/towns at $40 \%$, when it is seen from what it would have been; still the accessibility of public transport upon demand was minimal and limited.

Other important issues related to the availability of public transport were the issue of the average distance travelled to get into taxi/bus stops and the minimum waiting time to get transport service. While the average distance traveled to get into taxi/bus stops was reasonably fair and good enough, the minimum waiting time to get transport service, on the other hand, was by far daunting and too long. As shown in Table 4, the average walking distance to get into public transport was labeled as medium distance $(51.3 \%)$ followed by 'near distance' and 'very near distance' which was $27.7 \%$ and $25 \%$ respectively. However, regarding the issue of minimum waiting time to get into transport service, almost about $62.3 \%$ of the respondents replied that waiting for taxi/bus to get transport service took them more than 21-30 minutes and above. 
Table 4: Reliability and availability of transport service

\begin{tabular}{|c|c|c|c|c|c|c|c|c|c|}
\hline \multirow{2}{*}{\multicolumn{2}{|c|}{ Item }} & \multicolumn{6}{|c|}{ City/Town } & \multicolumn{2}{|c|}{ Total } \\
\hline & & Fr. & $\%$ & Fr. & $\%$ & Fr. & $\%$ & Fr. & $\%$ \\
\hline \multirow{2}{*}{$\begin{array}{llr}\text { Availability } & \text { of } & \text { public } \\
\text { transport } & \text { in } & \text { the } \\
\text { city/town } & & \end{array}$} & Yes & 16 & 16.0 & 36 & 36.0 & 34 & 34.0 & 86 & 28.7 \\
\hline & No & 84 & 84.0 & 64 & 64.0 & 66 & 66.0 & 214 & 77.3 \\
\hline \multirow{2}{*}{$\begin{array}{l}\text { Accessibility } \\
\text { demand }\end{array}$} & Yes & 33 & 33.0 & 42 & 42.0 & 45 & 45.0 & 120 & 40.0 \\
\hline & No & 67 & 67.0 & 58 & 58.0 & 55 & 55.0 & 180 & 60.0 \\
\hline \multirow{5}{*}{$\begin{array}{l}\text { Average walking } \\
\text { distance to get public } \\
\text { transport }\end{array}$} & Very near distance & 9 & 9.0 & 10 & 10.0 & 6 & 6 & 25 & 25.0 \\
\hline & Near distance & 26 & 26.0 & 29 & 29.0 & 28 & 28 & 83 & 27.7 \\
\hline & Medium distance & 49 & 49.0 & 51 & 51.0 & 54 & 54 & 154 & 51.3 \\
\hline & Far distance & 5 & 5.0 & 4 & 4.0 & 9 & 9 & 18 & 6.0 \\
\hline & Very far distance & 11 & 11.0 & 6 & 6.0 & 3 & 3 & 20 & 6.7 \\
\hline \multirow[t]{4}{*}{ Waiting Periods } & $1-10$ minutes & 5 & 7.5 & 12 & 20.7 & 10 & 18.2 & 27 & 15.0 \\
\hline & $11-20$ minutes & 18 & 26.9 & 9 & 15.5 & 14 & 25.5 & 41 & 22.8 \\
\hline & 21-30 Minutes & 25 & 37.3 & 10 & 17.2 & 7 & 12.7 & 42 & 23.3 \\
\hline & $\begin{array}{l}\text { More than } 30 \\
\text { Minutes }\end{array}$ & 19 & 28.4 & 27 & 46.6 & 24 & 43.6 & 70 & 39.0 \\
\hline
\end{tabular}

Source: Fieldwork, 2017

\subsection{Assurance of Urban Public Transport Service}

Assurance in the provision of urban public transport service is crucial. Public transport service devoid of security and customer handling as well as trustworthiness and good ethical qualities or technical expertise of operators affects the social development of the people and also exploits them economically. For this reason, effective urban public transport service requires these things to function well or/and to provide maximum possible service to the city dwellers.

Cognizant of this, the finding of the study showed that, the degree of security provided was relatively better and roughly labeled at $65 \%$ in all study areas. However, the degree of security is more problematic in Hawassa city $(42 \%)$ followed by Hosana (36\%) and Sodo town (26\%). Contrary to this, the degree of drivers' trustworthiness to the users, and possessions of desired ethical qualities and technical expertise on the job, was very lower which is rated as $20 \%$ and $26 \%$ respectively. This figure shows that, drivers and boarding staff are dubious and disrespectful to the users while providing transport service to the public. Compared to the three study areas, drivers are less trustworthy in Hosana town (16\%) followed by Sodo (19\%) and Hawassa (24\%). Likely drivers ethical qualities and technical expertise to help customers is lower in Hosana (18\%), followed by Hawassa (29\%), and Sodo (30\%).

\subsection{Empathy}

Table, 5 Transport assurance and degree of security

\begin{tabular}{|c|c|c|c|c|c|}
\hline \multirow[t]{3}{*}{ Items } & & \multicolumn{3}{|c|}{ City/Town } & \multirow[t]{2}{*}{ Total } \\
\hline & & \multirow{2}{*}{\begin{tabular}{|l|} 
Hawassa \\
$\%$
\end{tabular}} & \multirow{2}{*}{$\begin{array}{l}\text { Hosana } \\
\%\end{array}$} & \multirow{2}{*}{$\frac{\text { Sodo }}{\%}$} & \\
\hline & & & & & $\%$ \\
\hline \multirow{5}{*}{$\begin{array}{l}\text { Degree of security during Public Transport Service } \\
\text { Delivery }\end{array}$} & Very high & 6.0 & 3.0 & 5.0 & 4.7 \\
\hline & High & 11.0 & 12.0 & 13.0 & 12.0 \\
\hline & Medium & 41.0 & 49.0 & 56.0 & 48.7 \\
\hline & Low & 21.0 & 19.0 & 11.0 & 17.0 \\
\hline & Very Low & 21.0 & 17.0 & 15.0 & 17.7 \\
\hline \multirow{2}{*}{$\begin{array}{l}\text { Do drivers \& staffs help you to develop some degree of trust upon } \\
\text { them? }\end{array}$} & Yes & 24.0 & 16.0 & 19.0 & 19.7 \\
\hline & No & 76.0 & 84.0 & 81.0 & 80.3 \\
\hline \multirow{2}{*}{$\begin{array}{l}\text { Do drivers \& staffs possess the } \\
\text { desired ethical qualities and technical expertise }\end{array}$} & Yes & 29.0 & 18.0 & 30.0 & 25.7 \\
\hline & No & 71.0 & 82.0 & 70.0 & 74.3 \\
\hline
\end{tabular}

Source: Fieldwork, 2017

As indicated in Table 6, significant number of respondents replied that drivers and staffs had poor customer handling services. Accordingly, from the three study areas, $48.3 \%$ of respondents replied that customer handling and provision of satisfactory service by drivers and staffs is poor. Another significant number of respondents $(41.7 \%)$, replied that they do have a medium level of satisfaction. It is only $10 \%$ of respondents who replied that there is high level of customer handling and provision of satisfactory urban public transport service. Looking at 
the disaggregated data, Customers from Hosana (54\%) are not satisfied with the degree of empathy of drivers and staffs followed by customers from Hawassa (48\%).

Table 6: Empathy of Urban Public Transport Service Providers

\begin{tabular}{|c|c|c|c|c|c|}
\hline & & City/Town & & & Total \\
\hline & & Hawassa & Hosana & Sodo & \\
\hline Items & & $\%$ & $\%$ & $\%$ & $\%$ \\
\hline & Very high & 5.0 & 2.00 & 3 & 3.3 \\
\hline Degree of drivers' \& staffs' & High & 8.0 & 5.0 & 7 & 6.7 \\
\hline customer handling \& provision & Medium & 39.0 & 39.0 & 47 & 41.7 \\
\hline of & Low & 23.0 & 21.0 & 23 & 22.3 \\
\hline Satisfactory service & Very Low & 25.0 & 33.0 & 20 & 26.0 \\
\hline
\end{tabular}

Source: Fieldwork, 2017

\subsection{Tangibility of Urban Public Transport Services}

In this study, while analyzing the degree of passengers' satisfaction with urban public transport service, focus was made on seven different variables of tangibility as shown under Table 7. These variables of public transport tangibility constitute the overall physical conditions of vehicles and individuals' hygiene of vehicle operators and other boarding staffs. The result of the study shows that, the overall physical conditions of vehicles and individuals' hygiene of operators and other boarding staffs have a considerable negative effect on the degree of passengers' satisfaction with urban public transport in the study areas. Accordingly, the aggregate percentage of the overall variables included under tangibility is rated at $23.4 \%$. The table also shows that loading corresponding to vehicles seats, and individuals' hygiene of operators and boarding staffs is very low which is founded at $7.7 \%$ and $18 \%$ respectively. Contrary to this, sound disturbance and seats comfort inside the vehicle to some degree met the expectation of passengers at $45.7 \%$ and $40 \%$ respectively in all the study areas. However, there is still low satisfaction of customers with regard to ventilation $(23 \%)$, cleanness of vehicles (25\%), and enough space for legs $(28 \%)$.

Specifically, of all the three areas, the relative highest percentage of passengers' satisfaction is found in Hawassa and Sodo which is equally rated at $28 \%$. On the other hand, Hosana experienced the lowest percentage of passengers' satisfaction (23.9\%).

Table 7: Tangibility of urban Public Transport

\begin{tabular}{|c|c|c|c|c|c|c|c|c|c|}
\hline \multirow[t]{3}{*}{ Variables } & & \multicolumn{6}{|c|}{ City/Town } & \multirow{2}{*}{\multicolumn{2}{|c|}{ Total }} \\
\hline & & \multicolumn{2}{|c|}{ Hawassa } & \multicolumn{2}{|c|}{ Hosana } & \multicolumn{2}{|c|}{ Sodo } & & \\
\hline & & Fr. & $\%$ & Fr. & $\%$ & Fr. & $\%$ & Fr. & $\%$ \\
\hline \multirow[b]{2}{*}{$\begin{array}{l}\text { Drivers and staffs } \\
\text { keep their hygiene well }\end{array}$} & Yes & 17 & 17.0 & 17 & 17.0 & 20 & 20.0 & 54 & 18.0 \\
\hline & No & 83 & 83.0 & 83 & 83.0 & 80 & 80.0 & 246 & 82.0 \\
\hline \multirow[b]{2}{*}{$\begin{array}{l}\text { Loading } \\
\text { corresponds to Seats }\end{array}$} & Yes & 5 & 5.0 & 4 & 4.0 & 14 & 14.0 & 23 & 7.7 \\
\hline & No & 95 & 95.5 & 96 & 96.0 & 86 & 86.0 & 277 & 92.3 \\
\hline \multirow{2}{*}{\begin{tabular}{|l} 
Seats are \\
Comfortable \\
inside the vehicle \\
\end{tabular}} & Yes & 41 & 41.0 & 34 & 34.0 & 44 & 44.0 & 119 & 39.7 \\
\hline & No & 59 & 59.0 & 66 & 66.0 & 56 & 56.0 & 181 & 60.3 \\
\hline \multirow{2}{*}{$\begin{array}{l}\text { Enough space is } \\
\text { there for legs }\end{array}$} & Yes & 44 & 44.0 & 13 & 13.0 & 28 & 28.0 & 85 & 28.3 \\
\hline & No & 56 & 56.0 & 87 & 87.0 & 72 & 72.0 & 215 & 71.7 \\
\hline \multirow{2}{*}{$\begin{array}{l}\text { Vehicles are } \\
\text { Clean }\end{array}$} & Yes & 23 & 23.0 & 26 & 26.0 & 26 & 26.0 & 75 & 25.0 \\
\hline & No & 77 & 77.0 & 74 & 74.0 & 74 & 74.0 & 225 & 75.0 \\
\hline \multirow{2}{*}{$\begin{array}{l}\text { Ventilation (air } \\
\text { circulation) is }\end{array}$} & Yes & 15 & 15.0 & 27 & 27.0 & 26 & 26.0 & 68 & 22.7 \\
\hline & No & 85 & 85.0 & 73 & 73.0 & 74 & 74.0 & 232 & 77.3 \\
\hline \multirow{2}{*}{\begin{tabular}{|l} 
Sound \\
Disturbance \\
within vehicles \\
\end{tabular}} & Yes & 48 & 48.0 & 54 & 54.0 & 61 & 61.0 & 163 & 54.3 \\
\hline & No & 52 & 52.0 & 46 & 46.0 & 39 & $\beta 9.0$ & 137 & 45.7 \\
\hline
\end{tabular}

Source: Fieldwork, 2017 


\subsection{Responsiveness of Operators towards transport Users}

As indicated in Table 8, the degree of operators' responsiveness and cooperation to passengers is low in all study areas. Accordingly, the lowest level of operators' responsiveness is observed on the element of providing services as per transport rule which is rated at $24.7 \%$ followed by $26.7 \%$ of operators' notification while tariff change is made. Likely, only $31 \%$ of respondents replied that operators respect traffic rules. Besides, only $33 \%$ of respondents replied that operators are cooperatives to transport users. With regard to specific city and towns, even though the difference is insignificant, satisfaction of customers on operators' responsiveness is better in Sodo town at $(29 \%)$ followed by Hawassa $(22 \%)$. The lowest operators' degree of responsiveness and cooperation is found in Hosana town at $21 \%$.

Table 8: Operators Responsiveness to transport users

\begin{tabular}{|c|c|c|c|c|c|c|c|c|c|}
\hline \multirow[t]{3}{*}{ Variables } & & \multicolumn{6}{|c|}{ City/Town } & \multirow{2}{*}{\multicolumn{2}{|c|}{ Total }} \\
\hline & & \multicolumn{2}{|c|}{ Hawassa } & \multicolumn{2}{|c|}{ Hosana } & \multicolumn{2}{|l|}{ Sodo } & & \\
\hline & Response & Fr. & $\%$ & Fr. & $\%$ & Fr. & $\%$ & Fr. & $\%$ \\
\hline \multirow{2}{*}{\begin{tabular}{|l} 
Operators are \\
Cooperative
\end{tabular}} & Yes & 38 & 38.0 & 23 & 23.0 & 40 & 40.0 & 101 & 33.7 \\
\hline & No & 62 & 62.0 & 77 & 77.0 & 60 & 60.0 & 199 & 66.3 \\
\hline \multirow{2}{*}{\begin{tabular}{|ll|}
\multicolumn{2}{|l|}{ Operators notify } \\
tariff $\quad$ changes when \\
Made
\end{tabular}} & Yes & 16 & 16.0 & 30 & 30.0 & 34 & 34.0 & 80 & 26.7 \\
\hline & No & 84 & 84.0 & 70 & 70.0 & 66 & 66.0 & 220 & 73.3 \\
\hline \multirow[t]{2}{*}{\begin{tabular}{|lll}
$\begin{array}{l}\text { pperators respect all } \\
\text { traffic rules }\end{array}$ & & \\
\end{tabular}} & Yes & 12 & 12.0 & 9 & 9.0 & 10 & 10.0 & 31 & 10.3 \\
\hline & No & 88 & 88.0 & 91 & 91.0 & 90 & 90.0 & 269 & 89.7 \\
\hline \multirow{2}{*}{$\begin{array}{|ll|}\text { Operators } & \\
\text { Provide } & \text { Effective } \\
\text { service as per the rules }\end{array}$} & Yes & 22 & 22.0 & 21 & 21.0 & 31 & 31.0 & 74 & 24.7 \\
\hline & No & 78 & 78.0 & 79 & 79.0 & 69 & 69.0 & 226 & 75.3 \\
\hline
\end{tabular}

Source: Fieldwork, 2017

\subsection{Overall satisfaction level of urban public transport users}

The statistical distribution of respondents' on overall satisfaction with the existing urban public transport services in the study area is presented under Table 9. Accordingly, a close observation to the overall average percentage of reliability dimension of urban transport in all the study areas is around $45.8 \%$. But specifically, Hosana town has a better result of transport service reliability by $50.8 \%$ followed by Sodo at $50.2 \%$. A close observation to summary of variables of measuring assurance also shown that, the average level of customer satisfaction is $36.5 \%$. Hosana town has registered the lowest result at $32.6 \%$. Moreover, the cumulative average response about empathy shows that, the level of customer satisfaction is $51.7 \%$. Still Hosana town has the lowest level of customers' satisfaction by $46 \%$. Besides, the overall average response regarding tangibility dimension is $26.7 \%$. The result is very lower in Hosana town by $23.8 \%$. In addition, the overall average response about responsiveness is $23.9 \%$ in all the study areas. It is the lowest of all five dimensions used to measure customers' satisfaction. The lowest result is still registered in Hosana town.

Generally, the finding of the study showed that, the overall average rating of the five dimension of customers' satisfaction is $36.92 \%$. This is a very critical level. This being the case, Sodo town has the better level of customer's satisfaction by $40.26 \%$. But, Hosana town has the lowest level of customer's satisfaction by $34.8 \%$.

Table 9: Overall customer satisfaction on public transport service

\begin{tabular}{|l|l|l|l|l|}
\hline Dimensions & Hawassa & Hosana & Sodo & Total \\
\hline Reliability & 41.85 & 50.8 & 50.17 & 45.8 \\
\hline Assurance & 37 & 32.6 & 41 & 36.5 \\
\hline Empathy & 52 & 46 & 57 & 51.7 \\
\hline Tangibility & 28.14 & 23.85 & 24.42 & 26.7 \\
\hline Responsiveness & 22 & 20.75 & 28.75 & 23.9 \\
\hline Total & $\mathbf{3 6 . 1 9}$ & $\mathbf{3 4 . 8}$ & $\mathbf{4 0 . 2 6}$ & $\mathbf{3 6 . 9 2}$ \\
\hline
\end{tabular}

Source: Fieldwork, 2017

\section{Conclusion}

Customer satisfaction in all the study areas is insignificant. Not only customers' satisfaction but also the existence of urban public transport service is insufficient particularly with respect to the existing demand for the service. There is highest rate of popular mobility in all areas. But the available transport service is below the 
level of required demand. The level of the existing urban transport service is at infant stage and mostly underdeveloped.

The availability of larger sized city buses, capable of transporting large number of transport users at once are minimal and none existent in some areas. Dominantly, Bajaj or rickshaw motor taxis are available for public transport service. This made the level of customers' satisfaction in urban public transport service below $50 \%$.

Urban public transport service is neither reliable nor tangible or responsive to the customers in all the study areas. Even though, the three study areas are found at different level of socio-economic and political development, in terms of the level of customers' satisfaction, there is no significant difference among them. But, relatively speaking, Sodo town has a better level of customers' satisfaction on urban public transport services followed by Hawassa City. Contrarily, Hosana town has the lowest level of customers' satisfaction in urban transport service.

\section{Acknowledgment}

We would like to express your heartfelt gratitude to participants of this study who were cooperative to provide genuine data. We are also thankful to Transport Bureau of SNNPRS and Institute of Policy and Development Research of Hawassa University who provided a financial grant to conduct this study.

\section{Reference}

Baron, S. and Harris, K.(2003).Service Marketing. Text and Cases. 2ed. New York: Palgrave Macmillan. Consulting Engineering Service (India) Pvt. Ltd in Association with SABA Engineering PLC.

Bates, J., Polak J., Jones, P. and Cook A. (2001).The valuation of reliability for personal travel. Transportation Research, Part 37E, pp. 191-229

Beirão, G., and Cabral, J.A.S. (2007). Understanding attitudes towards public transport and private car: A qualitative study. Transport Policy, Vol. 14, pp. 478-489.

Berry, L. L., Parasuraman, A., \& Zeithaml, V. A., (1985).A conceptual model of service quality and its implications for future research. The Journal of Marketing, Vol. 49 No. 4, pp. 41-50.

Blery, E., Batistatos, N., Papastratou, E., Perifanos, I., Remoundaki, G., \&Retsina, M.(2009).Service quality and customer retention in mobile telephony.Journal of Targeting, Measurement and Analysis for Marketing, Vol. 17 No. 1, pp. 27-37.

Demdime, F. (2012). Demdime, F. (2012). Integrating Public Transport Networks and Built Environment: The Case of Addis Ababa and Experiences from Stockholm (Doctoral dissertation, Masters Thesis in Environmental Engineering and Sustainable Infrastructure, School of Architecture and the Built Environment, KTH-Royal Institute of Technology).

deOña, J., de Oña, R. and Calvo, F. J. (2012). A classification tree approach to identify key factors of transit service quality. Expert Systems with Applications, Vol. 39 No. 12, pp. 11164-11171.

Fellesson, M., \& Friman, M. (2012, February). Perceived satisfaction with public transport service in nine European cities. In Journal of the Transportation Research Forum, Vol. 47 No. 3.

Jonson, R. \& Clark, G. (2005).Service Operations Management. Improving Service Delivery (2nded.) London: Ashford Colour Press Ltd.

Ladhari, R. (2009). A review of twenty years of SERVQUAL research. International journal of quality and service sciences, Vol. 1 No. 2, pp. 172-198.

Nasution, M.N. (2010). Integrated Quality Management. Jakarta: Ghalia Indonesia.

Palmer, A. \& Cole, C.(1995).Service Marketing, Principles and Practice. United States of America: PrenticeHall, Inc.

Reitvield,P., Bruinsma, F.R., and Vuuren, D.J. V. (2001). Coping with unreliability in public transport chains: A case study for Netherlands. Transportation Research, Vol. 35A, pp. 539-559.

Sanjay, S. (2016). Assessment of Passenger Satisfaction with Public Bus Transport Services: A Case Study of Lucknow City (India). Studies in Business and Economics no. 11(3)/2016.

Thompson, K. Schofield, P. (2002). The Dimensions of Quality of Urban Public Transport-An Overseas.

Transportation Research Board (2004). Transit capacity and quality of service manual. TRCP Report 100 (2nded).

Sureshchandar, G. S., Rajendran, C., \&Anantharaman, R. N. (2002). Determinants of customer perceived service quality: a confirmatory factor analysis approach. Journal of services Marketing, Vol. 16 No. 1, pp. 9-34.

\section{About the Authors}

Robera Regassa Kenei is a Lecturer in the School of Governance and Development Studies, Hawassa University, Ethiopia. He holds BED degree in Civics and Ethical Studies from Mekele University. He also holds MA degree in International Relations from Addis Ababa University. Robera has research interest on areas of human rights, conflict studies, service delivery, gender, peace and development, and youth empowerment. 
Akalewold Fedilu Mohammed is a Lecturer in the School of Governance and Development Studies, Hawassa University. He obtained his BA degree in Governance and Development Studies and MA degree in Governance and Development Studies, specialization in 'Development Management' from the School of Governance and Development Studies, Hawassa University, Ethiopia. Akalewold's research interests focus on politics and governance, development project, public policy, poverty, community empowerment, children and people's work, and gender.

Degwale Gebeyehu Belay is a Lecturer in the Department of Governance and Development Studies, Bahir Dar University, Ethiopia. He holds a BA degree in Public Administration and Development Management, and MA degree in 'Regional and Local Development Studies' from Addis Ababa University, Ethiopia. He also holds an MA degree in Development Studies (Major in 'Social Policy for Development', specialization in 'Children and Youth Studies') from the International Institute of Social Studies of Erasmus University Rotterdam, the Netherlands. Degwale's research interest lies with issues of children and young people's work, employment, and migration; and public policy. 